\title{
ARQUITETURA PRÉ-MODERNISTA: ADOLF LOOS E A RACIONALIDADE DA FORMA
}

Liza da Fonseca Jeronymo', Francinne Xavier dos Santos' ${ }^{1}$, Mariana Malheiro Negrão Bandeira', Mariele Silva Ferragini', Valquíria Patricia Felix ${ }^{1}$, Valquíria Pereira Bastos ${ }^{1}$, Korina Costa ${ }^{2}$

${ }^{1}$ Discente do curso de Arquitetura e Urbanismo da Universidade do Oeste Paulista - UNOESTE. ${ }^{2}$ Docente do Curso de Arquitetura e Urbanismo da Universidade do Oeste Paulista - UNOESTE.

\section{RESUMO}

Arquiteto e teórico, Adolf Loos foi um grande pensador no final do século XIX ao início do século $\mathrm{XX}$, um dos criadores do modernismo. Na época, foi um dos pioneiros a romper com o historicismo, idealizando o abandono do ornamento e projetos mais limpos e racionais. Por meio de suas obras, deu início a novas características arquitetônicas, como o pé direito de diferentes alturas, o Raumplan, e seus inovadores terraço, presentes em grande parte de seus projetos. Nesse artigo, iremos analisar suas características e obras, ampliando o conhecimento na arquitetura pré-modernista e compreendendo as teorias de Adolf Loos, ao projetar uma arquitetura simples e nula de decorações.

Palavras-chave: Adolf Loos, arquitetura, pré-modernismo, ornamento, delito.

\section{INTRODUÇÃO}

Adolf Franz Karl Viktor Maria Loos foi um arquiteto e teórico, e se tornou conhecido por seus pensamentos radicais de abandono do ornamento. Seu estilo único, geométrico e racional, expressava seus ideais sobre a nova arquitetura que surgia no início do século XX.

Em 1908 publicou o seu mais famoso livro, "Ornament und Verbrechen" ("Ornamento e Delito"). Nele, Loos abordou assuntos sobre os arquitetos ornamentistas, considerando a decoração como um fenômeno do ponto de vista do homem civilizado, onde a evolução da cultura seria sinônimo de remoção dos ornamentos.

Neste período, a Europa vivenciava muitas transformações trazidas pela Revolução Industrial, tanto econômicas, quanto políticas-sociais, surgindo um novo modo de vida, com mudanças drásticas nas antigas tradições. As novas descobertas somadas à industrialização e ao capitalismo resultaram numa massificação dos produtos e evolução acelerada das tecnologias.

Já no contexto arquitetônico, desde a Arquitetura do Ferro, os novos materiais como o vidro e o aço deram origem aos novos edifícios, que separavam o fechamento da estrutura, possibilitando a abertura de grandes vãos e pés-direitos maiores. Logo após o movimento Art Noveau se destacou com suas curvas, decorações florais e escadas sinuosas. Outro destaque é o movimento Deutscher Werkbund, o Arts \& Crafts alemão, fundada por artistas e críticos com o objetivo de enobrecer o trabalho artesanal unido à arte e a indústria. 


\section{METODOLOGIA}

A investigação se fundamentará na abordagem qualitativa de pesquisa, utilizando-se da pesquisa de levantamento bibliográfico e da pesquisa documental, que segundo Teixeira (2000, p. 137), busca a correlação entre a teoria e os dados, entre o contexto e a ação, a partir da compreensão dos fenômenos por meio de sua descrição e interpretação. Para o trabalho com o estudo do tipo de levantamento bibliográfico ocorrerá inicialmente um levantamento das principais produções no contexto nacional de estudos, considerando a peculiaridade do objeto de estudo.

Desse modo, percebe-se que a pesquisa qualitativa vale-se do método indutivo, segundo o qual parte da observação, da análise dos fatos particulares, dos registros para compor um quadro compreensivo para então constituir a generalização universal, ou seja, a teoria. O processo de indução vale-se do princípio do empirismo, no qual o conhecer é dar significado à realidade (KÖCHE, 1997, p. 62).

A pesquisa foi desenvolvida com base nos livros que se tratavam da época e características da arquitetura e arte pré-modernistas. Também foi estudado os textos e obras de Adolf Loos. Entre eles, podemos citar sua obra "Ornamento e Delito", onde havia fotos, desenhos e informações sobre seus projetos realizados e seus ideais. Além de pesquisas na internet, foi somado o conhecimento adquirido em sala de aula.

\section{O RACIONALISMO LOOSIANO}

Adolf Loos nasceu em dezembro de 1870 em Brno, na República Tcheca, e morreu em Kalksburg, atual Viena, no dia 23 de agosto de 1933, aos 62 anos. Estudou no Royal e Imperial State Technical College, escola do Arts \& Crafts em Rechenberg, Bohemia, porém seus estudos se interromperam por dois anos devido ao exército. Cursou a Faculdade de Tecnologia de Dresden por três anos e viajou para os Estados Unidos a trabalho.

Começando como pedreiro, iniciou sua carreira em 1896 com o arquiteto Carl Mayreder e um ano depois começou a publicar seus artigos. Em 1988 publicou seu ensaio contra a Art Noveau, "A Cidade Potemkin"; em 1903 fundou a revista "Das Andere, Ein Blatt zur Einführung abendländischer Kultur in Österreich" e cinco anos depois apresentou o famoso "Ornamento e Delito". Em 1912 fundou a Escola de Arquitetura Bauschule, onde lecionou por dois anos, e por fim, em 1920 continuou seus estudos como arquiteto. 
Em seus textos expressava sua opinião adversa dos demais pensadores e arquitetos da época. Acreditava na verdade incontestável das suas idéias e afirmava que o pensamento de quem o contrariasse era não evolutivo.

Loos queria um método de construção inteligente baseado na razão e afirmava que tudo o que não pode ser justificado por motivos racionais seriam supérfluos e deveriam ser eliminado, considerando-o um atraso cultural.

Suas idéias também atacavam o design contemporâneo e o estilo imitativo do século XIX, impulsionado pelo Ecletismo, que segundo ele pode ser chamado de "lixo em massa". Sua obra representava a luta pela liberdade dos estilos decorativos, que impulsionou o Modernismo.

Uma de suas características era o desenvolvimento do projeto funcional e a distribuição dos ambientes com diferentes alturas de pé-direito, que pode ser visto em diversas obras. Um de seus projetos pode servir de exemplo para a técnica conhecida como Raumplan, a Casa Steiner. Projetada em 1910, em Viena, estava localizada em um zoneamento que proibia casas com mais de um piso. Assim, Adolf Loos projetou um telhado semi-circular que disfarçava os pisos superiores da casa.
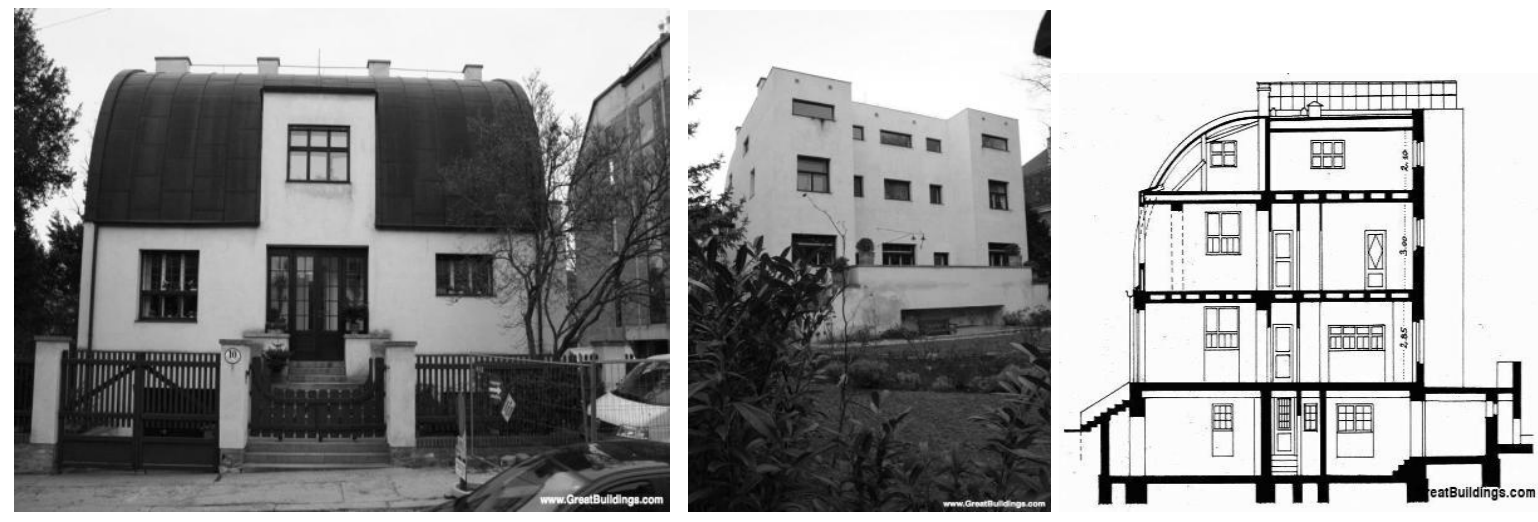

Figura 1. Fachada Frontal da Casa Steiner - Técnica do Raumplan

Figura 2. Fachada Posterior

Figura 3. Corte Longitudinal

Um dos autores que influenciou Adolf Loos foi Otto Koloman Wagner, arquiteto austríaco que acreditava que a nova arquitetura deve libertar-se de toda imitação sem deixar os elementos clássicos. Essa influência pode ser vista na obra de Loos, na Villa de Montreu e na casa de Michaelerplatz. 


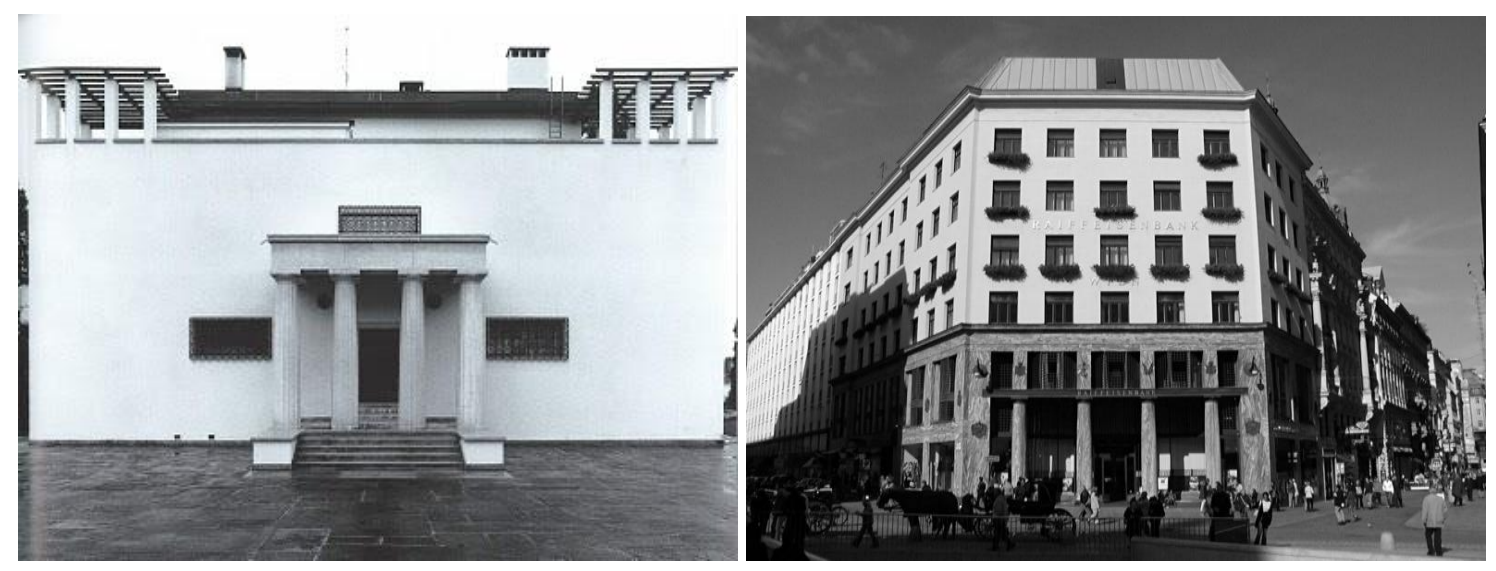

Figura 4. Colunas Dóricas - Villa Karma

Figura 5. Fachada do prédio de Michaelerplatz (Looshaus)

A colocação das janelas nos projetos de Loos se localizavam em determinados pontos da casa como propósito único a entrada de luz, já que ele não as considerava como um objeto paisagístico, e sim funcional.

Suas obras possuem fachadas discretas e interiores com materiais valiosos, como o mármore, mosaicos dourados, cristais e ladrilhos. Para Loos, a casa não tem que dizer nada ao exterior, e sim toda sua riqueza se manifestar no interior, permitindo a construção do íntimo.

Ele também inovou com os terraços de seus projetos, onde a cobertura plana da casa Sheu desempenharia um grande passo para a arquitetura pré-moderna, onde o próprio telhado foi concebido como um terraço ao ar livre. Dez anos depois Loos descreve as vantagens do telhado plano em um artigo sobre o projeto feito em 1923 para o terraço do hotel Grand Hotel Babylon: "Desde a descoberta do teto de concreto armado, cobertura de cascalho e, a partir da utilização de asfalto, você pode executar ambas as coberturas planas e terraços." (LOOS, 1923)

Adolf Loos foi vítima das críticas da época em vários projetos. Um deles, Looshaus, teve sua obra interrompida até que Loos ornamentasse o edifício. Era construído no centro de Viena e não possuía ornamentos, causando polêmica e contrastando com o seu entorno. Assim, o arquiteto teve que inserir floreiras abaixo das janelas, ornamento com ritmo e simplicidade, podendo continuar com sua obra tranquilamente. (Figura 2)

Loos também costumava aproveitar o desnível do terreno, como na Casa Steiner e a Casa Moller. Cercada por morros, essa casa foi elogiada pela sua fachada cúbica, com o uso do Raumplan de maneira inovadora. Os espaços internos foram concebidos de formas diferentes e não-modernas. 

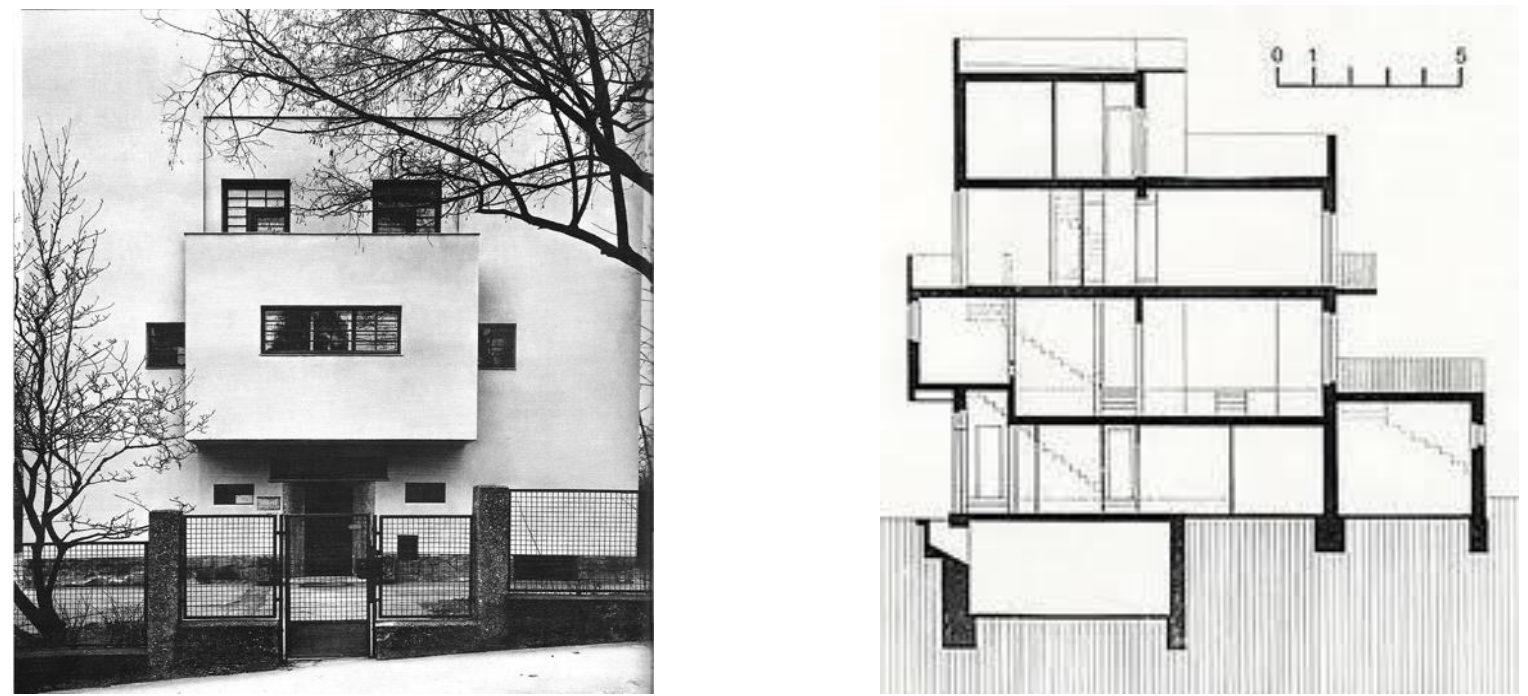

Figura 6. Fachada principal

Figura 7. Corte

\section{CONCLUSÃO}

Com o presente artigo, procuramos nos aprofundar na arquitetura pré-modernista através de um de seus maiores representantes, Adolf Loos. Sua busca pela arquitetura pura, geométrica e simplista vem influenciando durante décadas muitos dos mais famosos arquitetos do mundo.

Apesar de sempre ser muito criticado, tornou-se o precursor deste estilo arquitetônico. Podemos notar sua influência nos centros históricos, como Paris e Viena, ao nos depararmos com sua obra simples que se destaca no entorno ornamentado.

Com sua ideologia, conseguiu superar as dificuldades e avançar na carreira e ser reconhecido mundialmente, com seu trabalho como arquiteto e estudos sobre a evolução da tecnologia e críticas aos ornamentos historicistas.

\section{REFERÊNCIAS}

BENEVOLO, Leonardo. História da Arquitetura Moderna. 4. ed. Perspectiva, 2009.

Art Market. Adolf Loos Biography - Infos. Disponível em: < http://www.adolf-loos.com/>. Acesso em: 03 jun. 2013.

DALZELL, W. R.. Arquitetura. 2. ed. Melhoramentos, 1977.

LOOS, Adolf. Adolf Loos: Ornamento y Delito y otros escritos. 1. ed. Gustavo Gili, 1972.

Vitruvius. 0 fracasso da utilidade. Disponível em: <http://www.vitruvius.com.br/revistas/read/arquitextos/08.089/201>. Acesso em: 04 jun. 2013.

Great Buildings. Adolf Loos. Disponível em:

<http://www.greatbuildings.com/architects/Adolf_Loos.html>. Acesso em: 04 jun. 2013. 
DEMPSEY, Amy. Estilos, Escolas e Movimentos. 1. ed. Cosac \& Naify, 2002.

Cafe Museum. History \& Press Info. Disponível em: < http://www.cafemuseum.at/en/cafemuseum/history-press-info/html>. Acesso em: 04 jun. 2013.

Urbipedia. Cafe Museum. Disponível em:

http://www.urbipedia.org/index.php/Caf\%C3\%A9_Museum>. Acesso em: 04 jun. 2013.

WikiArquitetura. Villa Karma. Disponível em: <

http://en.wikiarquitectura.com/index.php/Villa_Karma >. Acesso em: 04 jun. 2013.

WikiArquitetura. Casa Steiner. Disponível em: < http://es.wikiarquitectura.com/index.php/Casa_Steiner >. Acesso em: 04 jun. 2013.

Monte de Palavras. Adolf Loos, Arquitetura de Primeira. Disponível em: < http://montedepalavras.blogspot.com.br/2012/09/adolf-loos-arquitectura-de-primeira.html>. Acesso em: 04 jun. 2013.

WikiArquitetura. Villa Moller. Disponível em: < http://en.wikiarquitectura.com/index.php/Villa_Moller >. Acesso em: 05 jun. 2013. 